\title{
Compreendendo o papel de Foz do Iguaçu/PR na rede de cidades com base nos deslocamentos pendulares
}

\author{
Comprender el papel de Foz do Iguaçu/PR em la red de \\ ciudades a través de desolazamientos turnos
}

\section{Understanding the role of Foz do Iguaçu/PR in the network of cities through commuting shifts}

\author{
Cláudia Heloiza Conte \\ claudiaheloiza@yahoo.com.br \\ Universidade Estadual de Maringá
}

Resumo: O presente trabalho tem como objetivo compreender a dinâmica existente entre Foz do Iguaçu, as cidades da rede urbana regional e as vizinhas sul americanas Ciudad Del Este no Paraguai e Puerto Iguazu na Argentina com base nos deslocamentos pendulares. Para tanto se fez necessário o entendimento conceitual sobre redes urbanas, assim como das principais características e elementos dos deslocamentos pendulares. Com esta compreensão e com dados provenientes de levantamentos de campo tivemos subsídio para traçar uma análise sobre parte da dinâmica existente entre estas cidades.

Palavras-chave: Dinâmica. Deslocamentos pendulares. Foz do Iguaçu. Rede urbana.

Resumen: El presente trabajo tiene como objetivo comprender la dinámica entre Foz do Iguaçu, La red urbana de ciudades de la región y los vecinos de America Del Sur, Ciudad Del Este en Paraguay y Puerto Iguazú em Argentina sobre la base de los desplazamientos turnos. Para eso, fue necesaria la comprensión conceptual de las redes urbanas, así como las principales características y elementos de conmutación turnos. Com este entendimiento y con datos de encuestas sobre el terreno, la asignación tuvo que recurrir a un analisis de la dinámica entre estas ciudades.

Palavras clave: Dinámica. Desplazamientos turnos. Foz do Iguaçu. Red urbana.

Abstract: The present work aims to understand the dynamic between Foz do Iguaçu, the urban network of regional cities and the neighboring South American Ciudad del Este in Paraguay and Puerto Iguazu in Argentina based on commuting shifts. For this purpose it was necessary conceptual understanding on urban networks, as well as the main characteristics and elements of commuting shifts. With this understanding and with data from field surveys, allowance had to draw on an analysis of the dynamics between these cities.

Keywords: Dynamic. Commuting shifts. Foz do Iguaçu. Urban network. 


\section{INTRODUÇÃO}

A partir da década de 1970, fortes transformações afetaram a cidade de Foz do Iguaçu, caracterizando-se como momento de importantes mudanças na evolução deste centro urbano. A partir de então, Foz do Iguaçu teve evolução rápida e intensa, mediante a construção da Usina Hidrelétrica de Itaipu, que afetou não somente a cidade, mas também a rede urbana regional e as cidades fronteiriças de Ciudad Del Este, no Paraguai, e Puerto Iguazu, na Argentina. A construção de Itaipu alterou radicalmente a evolução e a dinâmica funcional da cidade, bem como as relações econômicas e sociais estabelecidas pela mesma com sua rede e com cidades de outras redes. Na Figura 01, observa-se que a cidade de Foz do Iguaçu está localizada no extremo oeste do Paraná, na confluência dos rios Paraná e Iguaçu e, ao mesmo tempo, na divisa entre o Brasil, Paraguai e Argentina, área esta denominada de Tríplice Fronteira. A figura permite ainda observar a localização das cidades de Ciudad Del Este, no Paraguai, e Puerto Iguazu, na Argentina, que conformam uma aglomeração urbana.

Nesta perspectiva, cabe considerar que a Secretaria de Planejamento do Estado do Paraná aponta que as aglomerações podem ser classificadas em duas categorias: as de espaço urbanizado contínuo, resultantes da expansão da cidade central, da expansão simultânea de duas ou mais cidades e/ou de uma integração de cidades, enquanto as aglomerações sem espaço urbanizado contínuo são formadas por municípios contíguos, cuja integração é feita por complementaridade de funções e não por junção espacial (PARANÁ, 1991).

Destaque deve ser dado para as aglomerações fronteiriças, cujas áreas de ocupação contínua, resultantes da expansão urbana de cidades vizinhas, mesmo que cortadas por rios perpassam e interconectam territórios de mais de um país. No estudo de uma determinada aglomeração de fronteira, um ponto fundamental para a compreensão diz respeito às migrações e/ou deslocamentos pendulares. 
Figura 1 - Localização de Foz do Iguaçu/PR

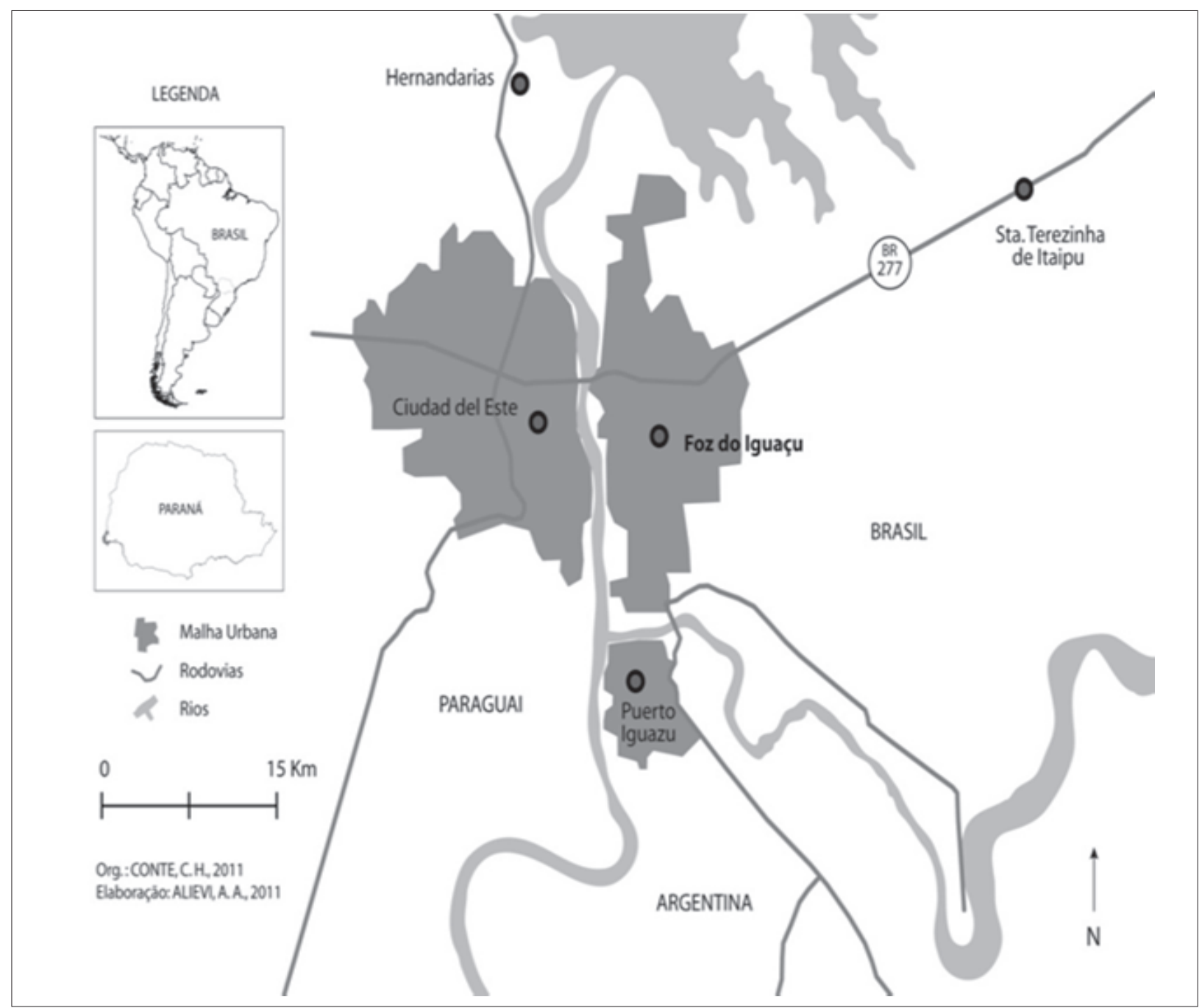

No período compreendido entre as décadas de 1970 e 1990 - quando a Usina Hidrelétrica de Itaipu foi construída no Rio Paraná -, Foz do Iguaçu atraiu um enorme contingente populacional, teve sua área urbana fortemente ampliada e ocorreram profundas alterações nas atividades econômicas, tanto no comércio como nos serviços, enquanto a industrialização não teve destaque. O município, que até então tinha uma economia apoiada principalmente nas atividades agropecuárias, passou a ter no turismo, comércio e serviços, sua base econômica.

Considerando o conjunto de alterações socioespaciais ocorridas em território iguaçuense, bem como nas cidades de sua rede urbana regional e nas vizinhas Ciudad Del Este/Py e Puerto Iguazu/Ar, consideramos os deslocamentos pendulares como metodologia para a compreensão da dinâmica existente entre tais cidades e Foz do Iguaçu. Entende-se que os deslocamentos pendulares da população para trabalho e/ ou estudo em município que não o de residência constitui um dado que vem sendo usado para captar dinâmicas territoriais, especialmente relacionadas à urbanização. Estes movimentos acontecem, principalmente, motivados pela dissociação entre local de moradia e local 
de trabalho, considerando a concentração de atividades ligadas a produção e consumo, geralmente em municípios de maior porte.

Os procedimentos operacionais para a elaboração deste estudo abrangeram o uso de fontes secundárias e primárias. As fontes secundárias constituem-se em referencial teórico sobre as temáticas discutidas, em dados obtidos em publicações do IBGE e IPARDES, Ministério do Trabalho e Emprego, dentre outros. As fontes primárias referem-se à obtenção de dados em órgãos públicos municipais e federais, instituições da sociedade civil, empresas privadas, dentre outros.

Para atingir os objetivos propostos, o trabalho foi estruturado em três partes. A primeira delas apresenta uma breve discussão sobre conceito e características da rede urbana, posteriormente são abordadas questões acerca dos deslocamentos pendulares, para finalmente analisar os descolamentos pendulares em direção a Foz do Iguaçu.

\section{REDE URBANA: COMPREENDENDO O CONCEITO}

A temática de rede urbana é abordada através de distintos elementos e/ou categorias analíticas, sendo os estudos sobre a hierarquia urbana os mais numerosos e tradicionais. Christaller, estudioso alemão, em 1933, escreveu a teoria das Localidades Centrais, explicando a distribuição de bens e serviços pelas cidades. $\mathrm{O}$ autor verificou que existe distinção entre a distribuição de bens e serviços entre as cidades, vinculada diretamente ao tamanho dos núcleos.

As proposições de Christaller referem-se à análise dos núcleos urbanos diversos, entendidos como localidades centrais, nos quais se realizam funções centrais de distribuição de bens e serviços a uma população residente em sua área de influência. Para o autor, as localidades centrais apresentam diferentes níveis de centralidade, enquanto graus variados de importância, a partir das funções centrais desempenhadas.

De acordo com a teoria das localidades centrais, a rede urbana pode ser compreendida segundo a função das localidades, pois “[...] existem princípios gerais que regulam o número, tamanho e distribuição dos núcleos de povoamento: grandes, médias, pequenas cidades, e ainda minúsculos núcleos semi-rurais, todos são considerados como localidades centrais" (CORRÊA, 1989, p. 21). Todas as cidades contam com atividades de distribuição de bens e serviços para uma determinada área de influência, ou seja, em posição central perante demais localidades.

A centralidade de um núcleo é medida pelo seu grau de importância com base em suas funções centrais. Quanto maior número de funções, maior a sua região de influência, maior a população externa atendida e, portanto, maior a sua centralidade. Ou seja, a oferta de bens e serviços está relacionada ao tamanho do núcleo e de sua área de influência.

Nesta perspectiva, cabe apontar que entendemos rede urbana enquanto "[...] um conjunto de centros funcionalmente articulados [...]" (CORRÊA, 1989, p. 8), onde é por meio "[...] das numerosas cristalizações materiais diferenciadas do processo de distribuição varejista e de serviços, que se realiza em um amplo território sob o domínio do capitalismo a articulação entre produção propriamente dita e o consumo final [...]" 
(CORRÊA, 1989, p. 20), ou seja, a rede urbana seria a concretização do mercado de distribuição no sistema capitalista.

Sendo assim, Corrêa (1997) a considera enquanto estrutura territorial:

A rede de localidades centrais é o que ela é pelo fato de se constituir em uma estrutura territorial da sociedade através da qual se pode verificar a reprodução de classes sociais distintas tanto entre si como em suas localizações, reprodução esta que interessa à classe dominante localizada [...] (CORRÊA, 1997, p. 24).

Deve-se compreender paralelamente que a gênese e a dinâmica de uma rede urbana fazem parte do processo histórico, conferindo a esta uma natureza social, tornando-a uma dimensão socioespacial da sociedade, refletindo e condicionando a sociedade que a engendrou (FRESCA, 2004). Por isso, a rede urbana é “[...] um produto social, historicamente contextualizado, cujo papel crucial é o de, através de interações sociais espacializadas, articular toda a sociedade numa dada porção do espaço, garantindo a sua existência e reprodução (CORRÊEA, 1997, p. 93).

Considerando a rede urbana como uma dimensão socioespacial da sociedade ou como uma estrutura territorial, os processos de criação, apropriação e circulação do capital excedente, ao ocorrerem internamente ou externamente a rede, estão em constantes modificações. Isso se dá pelo fato de estarem também relacionados à divisão territorial do trabalho, que por sua vez também sofre mudanças com o passar do tempo.

Como consequência das necessidades relacionadas à produção, circulação e consumo no âmbito do capitalismo - decisão, produção, concentração, beneficiamento, armazenamento, venda no varejo, consumo final e, ainda, tendo em vista o alcance espacial máximo e mínimo dos consumidores e empresas no amplo território -, " [...] torna-se necessária a existência de vários pontos interferindo no processo de circulação. Estes pontos são os centros urbanos" (CORRÊA 2006, p. 29).Parte do valor excedente, no processo de circulação entre esses pontos é reinvestida, voltando a circular e, desta forma, gerando novos fluxos.

Para Ribeiro (1998, p. 63), a rede urbana sob o capitalismo representa:

Uma estratégia logística na acumulação de capital, que tem como expressão as cidades, dotadas continuamente de meios técnicos científicos, entre eles [...] um sistema de comunicação [...] e meios de transportes [...] que permitem a expansão do mercado.

Como mencionado anteriormente, a rede urbana é ainda uma condição para a divisão territorial do trabalho, visto que através dela, os maiores centros urbanos de produção, circulação e acumulação emitem decisões, investimentos e inovações a fim de gerar fluxos distintos, criando e transformando desigualmente cidades e atividades (SANTOS, 1996).

Desta forma, a rede urbana enquanto uma dimensão espacial da sociedade, intermediada pela criação, apropriação e circulação do valor excedente, implica no reinvestimento deste excedente acumulado em novas atividades produtivas, para que se amplie a reprodução do capital e novos excedentes sejam gerados. Corrêa (1989, p. 51) 
aponta que este reinvestimento pressupõe a existência de fluxos diversos, abrangendo pessoas, bens e serviços, dinheiro, ideias, ordens, entre outros, e a existência de centros urbanos de uma rede urbana onde ocorram os processos de tomada de decisões, armazenamento, vendas no atacado e varejo, transformações industriais e prestação de serviços.

Nesta discussão, Harvey (1980, p. 204) explicita que as "cidades [e por extensão as redes urbanas] podem ser consideradas como formas criadas para mobilização, extração e concentração geográfica de quantidade significativa do produto excedente socialmente definido". Nesta perspectiva, que é a rede urbana, cada cidade deve desempenhar de alguma forma um determinado papel, pois caso contrário, terá inviabilizada a sua existência.

Enquanto uma forma espacial, por meio da rede urbana, são efetuadas funções como a comercialização da produção rural, produção industrial, comércio atacadista, varejista, prestação de serviços etc., que " reportam-se aos processos sociais, dos quais a criação, apropriação e circulação do valor excedente constitui-se no mais importante, ganhando características especificas na estrutura capitalista" ( CORRÊE, 1989, p. 71).

Com esta base conceitual e no intuito de alcançar o entendimento da dinâmica existente na rede urbana de Foz do Iguaçu, se faz necessário discutir elementos relacionados aos deslocamentos pendulares.

\section{OS DESLOCAMENTOS PENDULARES}

Corrêa (1997) considera o fenômeno da mobilidade como um dos elementos que integram as interações espaciais. De acordo com o autor, estas se referem ao fluxo de trabalhadores, consumidores e turistas, além de produtos e informações que se dinamizam e reproduzem o espaço. Em relação à mobilidade da população, o autor revela a complexidade do fenômeno que participa do processo de transformação social do mundo contemporâneo.

Deslocamentos pendulares, entendidos como deslocamentos diários do domicílio para o trabalho e estudo, se constituem importante fator para a análise do processo de aglomeração. Os deslocamentos pendulares constituem critério fundamental para a delimitação e estabelecimentos de regiões metropolitanas, áreas metropolitanas e aglomerações urbanas. Estes deslocamentos pendulares tornam-se cada vez mais complexos na medida em que incluem distintas situações relacionadas ao tamanho das aglomerações urbanas; dos tipos, condições e número de empregos ofertados entre as cidades de uma aglomeração; das formas de transporte, das áreas residenciais, entre outras.

É importante destacar que os censos demográficos do IBGE definem deslocamento pendular como aquele deslocamento diário que uma pessoa efetua entre seus locais de trabalho/estudo, quando estes se localizam em municípios distintos. A operacionalização realizada pelo IBGE não especifica sobre a frequência destes deslocamentos e desconsidera 
o meio de transporte utilizado na viagem, a distância percorrida ou o custo monetário e de tempo (IBGE, 2001).

Os deslocamentos pendulares da população para trabalho e/ou estudo em município que não o de residência compõe uma informação que vem sendo utilizada para captar dinâmicas territoriais, particularmente associadas à urbanização (MOURA, 2010). Tais movimentos ocorrem, majoritariamente, motivados pela dissociação entre local de trabalho e local de moradia, dada a concentração de atividades relacionadas a produção e consumo, em geral em municípios de maior porte.

Neste sentido, Moura (2010, p. 44) explicita que:

No caso das aglomerações urbanas, estão condicionados à distribuição e hierarquia de funções entre os municípios integrantes. São evidenciados também entre municípios não aglomerados, quando expressam a localização de atividades atrativas para trabalho e/ou estudo, muitas vezes decorrentes apenas de uma grande indústria, um grande estabelecimento de comércio ou serviços, uma cooperativa, uma empresa agropecuária ou uma universidade.

Nesta discussão, Ojima (2011) explicita que, geralmente, a discussão sobre a mobilidade pendular está associada à expansão das cidades, a sua área de influência em relação à centralidade do mercado de trabalho. Para o autor, existe uma relação direta entre migração pendular, mobilidade residencial, mobilidade cotidiana e espaço da vida.

A mobilidade residencial está relacionada aos deslocamentos da população no interior de uma determinada unidade administrativa, a mobilidade cotidiana está associada à mobilidade residencial e as migrações intrametropolitanas, entretanto, estes movimentos da população normalmente não alteram o espaço. Embora o trabalho tenha centralidade nos deslocamentos cotidianos, a mobilidade cotidiana é mais abrangente, visto que envolve as diferentes ações do dia a dia dos indivíduos.

Desta forma, as migrações pendulares constituem a distribuição espacial da população, em seus distintos aspectos, cujas modalidades estão ligadas entre si, a partir das migrações internas, da mobilidade residencial, da mobilidade cotidiana e ao espaço de vida (OJIMA, 2011).

Além da busca por trabalho e estudo, os deslocamentos têm sido manifestados também por causas atrativas, como é o caso do consumo. Este é “[...] movimento da população de seu habitat até um local de consumo de mercadorias que tende a se realizar movido por questões econômicas, sociais e culturais" (GUIZO e ROCHA, 2008, p. 109).

Neste sentido, os autores acrescentam:

No que se refere à mobilidade do consumo, gostaríamos de salientar que, devido à relatividade que na contemporaneidade foi estabelecida entre tempo e tecnologia, incrementada principalmente com os avanços do meio-técnico e do meio-técnicocientífico-informacional, esta ordem de mobilidade pôde se realizar em diversas escalas, desde as realizadas nas redes urbanas, até aquelas que se concretizam numa espacialidade internacional, mesmo que numa temporalidade relativamente curta. [...] vale ressaltar, por exemplo, o caso dos sacoleiros do Brasil que se direcionam para 
o Paraguai para realizar suas compras, ou ainda de países vizinhos que se direcionam para espacialidades específicas do território brasileiro, como os shoppings atacadistas de confecções da cidade de Maringá e de Cianorte, também para este fim (GUIZO e ROCHA, 2008, p. 110).

Moura (2010) afirma que os municípios com as maiores proporções de fluxos pendulares são aqueles localizados em regiões industrializadas e de serviços, onde a divisão territorial do trabalho é mais nítida e a valorização do solo urbano expande as periferias, que se tornam reduto de moradia de trabalhadores em atividades localizadas em outras partes das cidades.

Analisando o Estado do Paraná, a autora aponta que, consoantes aos fluxos que definem a região de influência das cidades, os fluxos dos movimentos pendulares da população para trabalho e/ou estudo em município distinto do de residência determinam a abrangência física dos deslocamentos frequentes, induzida pelos distintos papéis exercidos pelos municípios que compõem os três principais arranjos espaciais:

[...] o configurado pelas aglomerações urbanas de Londrina e Maringá, no Norte do Estado; o que agrega a aglomeração de Cascavel/Toledo e a aglomeração transfronteiriça de Foz do Iguaçu, no Oeste; e o arranjo urbano-regional de Curitiba - unidade espacial configurada pela aglomeração metropolitana de Curitiba, aglomeração de Ponta Grossa, Carambeí e Castro e ocupação contínua litorânea, polarizada por Paranaguá (MOURA, 2010, p. 52).

Cada uma destas aglomerações urbanas possui singularidades relacionadas às características econômicas, sociais e culturais. É nesta perspectiva que a próxima parte se atém à discussão dos deslocamentos pendulares na rede de Foz do Iguaçu.

\section{OS DESLOCAMENTOS PENDULARES EM FOZ DO IGUAÇU}

A fim de melhor compreender o processo do deslocamento pendular, realizamos um levantamento do número de passageiros que utiliza o transporte intermunicipal entre Foz do Iguaçu e as cidades de Santa Terezinha de Itaipu, Missal, São Miguel do Iguaçu, Marechal Cândido Rondon e Santa Helena.

A Figura 2 apresenta a rede urbana regional de Foz do Iguaçu (IBGE, 2008). Observa-se que Foz do Iguaçu, por mais complexa que seja do ponto de vista de suas atividades comerciais e de seus serviços, é considerada um centro sub-regional A. Sua rede urbana regional é composta por seis cidades: Santa Terezinha de Itaipu, São Miguel do Iguaçu, Medianeira, Serranópolis do Iguaçu, Missal e Itaipulândia. 
Figura 2 - Rede urbana de Foz do Iguaçu: 2007

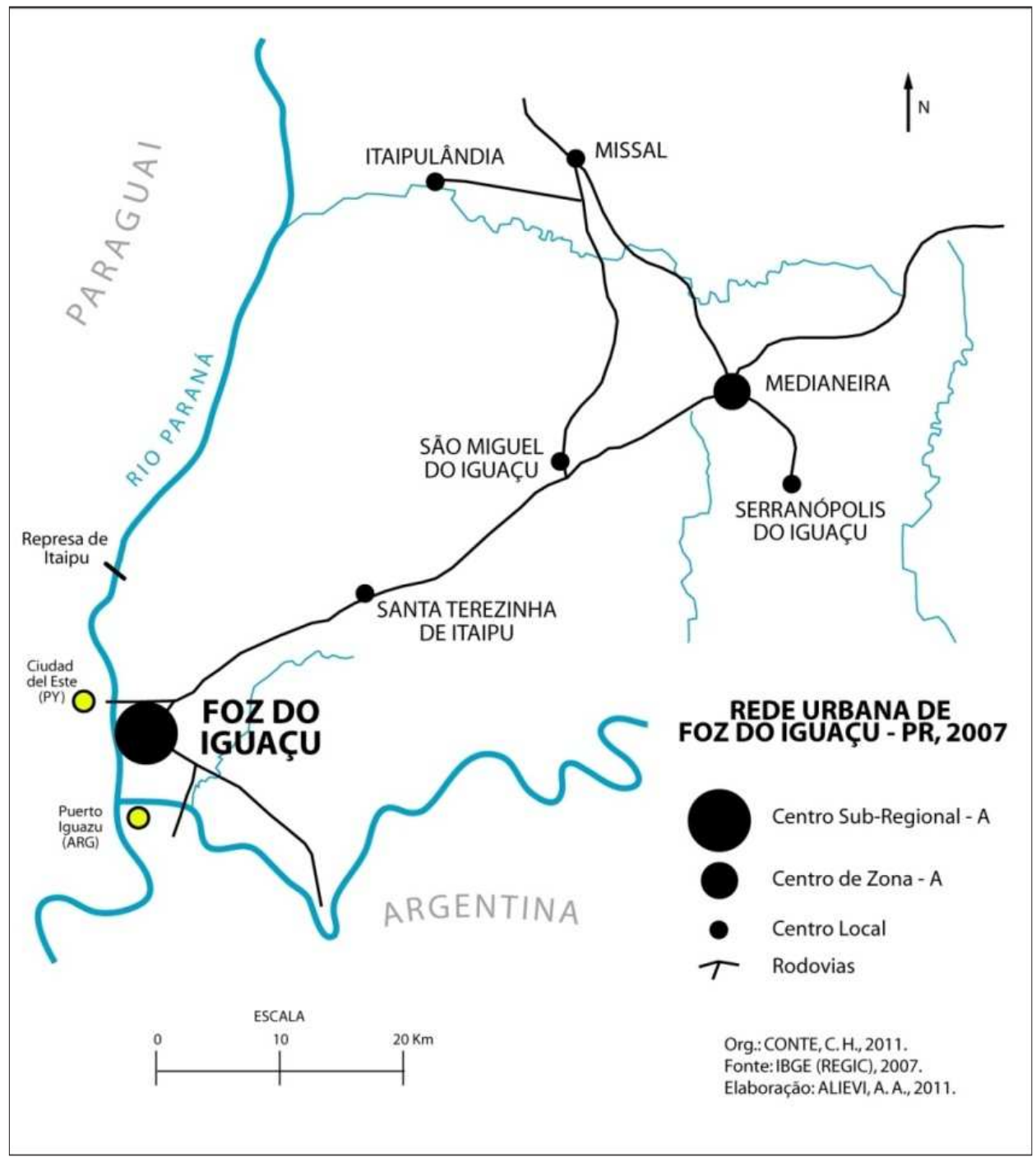

Das seis cidades que se encontram sob influência direta de Foz do Iguaçu, apenas Serranópolis do Iguaçu e Medianeira não possuem transporte coletivo metropolitano, fato que impossibilitou considerá-las nesta pesquisa, já que as analises foram elaboradas com base nos dados fornecidos pelas empresas que realizam este serviço.

Importante destacar que a Linha Foz-Marechal Cândido Rondon-Santa Helena também atende o município de Itaipulândia. Neste caso, o número de passageiros não é específico por cidade, isto é, o número de pessoas que utiliza a linha Foz-Santa Helena é o total de pessoas originárias de Marechal Cândido Rondon, Santa Helena e Itaipulândia.

A Tabela 1 demonstra que a linha entre Foz do Iguaçu e São Miguel do Iguaçu é a mais utilizada, já que diariamente 1.055 pessoas utilizaram este serviço entre os meses de janeiro a julho de 2011. É um número expressivo, principalmente se considerarmos a relação entre esta linha e a linha que realiza Foz do Iguaçu, Marechal Cândido Rondon e Santa Helena, que além destas três cidades, ainda transporta pessoas do município de Itaipulândia. Se dividirmos a média diária desta linha por quatro, verificamos que uma 
média de 182 pessoas de cada uma destas quatro cidades foi ou voltou de Foz do Iguaçu no primeiro semestre de 2011.

Tabela 1 - Média mensal e diária de passageiros do transporte metropolitano de Foz do Iguaçu: janeiro-junho de 2011

\begin{tabular}{c|c|c}
\hline Linhas & Média mensal de passageiros & Média diária de passageiros \\
\hline Foz-Missal-Foz & 18.030 & 601 \\
\hline Foz-São Miguel-Foz & 31.650 & 1.055 \\
\hline Foz-Marechal-Sta.Helena-Foz & 21.840 & 728 \\
\hline Total & 71.520 & 2.384 \\
\hline
\end{tabular}

Fonte: Princesa dos Campos, 2011.

Em relação aos deslocamentos entre as cidades de Foz do Iguaçu e São Miguel, podemos afirmar que este é motivado principalmente por estudo, pois de acordo com dados obtidos nas faculdades e universidades da cidade, um grande número de pessoas desta localidade recorre a Foz do Iguaçu com o intuito de frequentar uma instituição de ensino superior. Além da educação, atraídas pela proximidade existente entre estas duas cidades (cerca de 40 quilômetros), muitas pessoas se deslocam diariamente até Foz do Iguaçu, motivadas pelo trabalho, além da busca por serviços e comércio.

A dinâmica no setor de transporte coletivo existente entre as cidades de Foz do Iguaçu, Marechal Cândido Rondon, Santa Helena e Itaipulândia, além de ser notadamente menor, ainda guarda algumas peculiaridades: os municípios de Marechal Cândido Rondon e Santa Helena localizam-se mais próximos a Cascavel do que Foz do Iguaçu ${ }^{1}$. Além de a distância ser menor, o acesso é mais fácil, já que existe uma rodovia direta entre estes dois municípios e Cascavel. Desta forma, a linha proveniente de Marechal Cândido Rondon acaba por servir mais pessoas de Itaipulândia, cujos passageiros também realizam o deslocamento pendular para Foz do Iguaçu objetivando trabalho, estudo e/ ou consumo de bens e serviços.

Observa-se na Tabela 1 que a linha Foz-Missal-Foz totalizou média de 601 deslocamentos diários entre as cidades. Estes dados evidenciam um grande fluxo, principalmente se considerarmos que Missal possui uma população total de 10.474 (IBGE, 2010) pessoas. Os motivos destes deslocamentos são os mesmos destacados anteriormente.

A Tabela 2 apresenta os dados relacionados ao transporte metropolitano entre Foz do Iguaçu e Santa Terezinha de Itaipu. Esta análise foi elaborada separadamente, pois os dados fornecidos pela empresa responsável pela linha especificam números de idas e números de voltas entre as respectivas cidades.

1 De acordo com o DER, a distância entre Foz do Iguaçu e Marechal Cândido Rondon é de 164 quilômetros, enquanto Santa Helena dista 120 quilômetros. Já a distância entre Marechal Cândido Rondon e Cascavel é de 83 quilômetros e Santa Helena dista 100 quilômetros de Cascavel. 
Tabela 2 - Média mensal e diária de passageiros do transporte metropolitano entre Foz do Iguaçu e Santa Terezinha de Itaipu: janeiro-junho de 2011

\begin{tabular}{c|c|c}
\hline Linhas & Média mensal de passageiros & Média diária de passageiros \\
\hline Foz-Santa Terezinha de Itaipu & 48.330 & 1.611 \\
\hline Santa Terezinha de Itaipu - Foz & 43.470 & 1.449 \\
\hline Total & 91.800 & 3.060 \\
\hline
\end{tabular}

Fonte: Viação Itaipu, 2011.

Santa Terezinha de Itaipu conta com uma população urbana de 18.837 habitantes (IBGE, 2010), que utiliza os serviços e o comércio de Foz do Iguaçu diariamente, além de um grande número de trabalhadores direcionarem-se para a cidade vizinha. Isso é confirmado através dos dados, já que diariamente 1.449 pessoas deslocam-se sentido Foz do Iguaçu.

Em relação aos movimentos com destino a outros países, o estado do Paraná destaca-se por concentrar quase um terço do total desse tipo de fluxo no país, fundamentalmente em função da mobilidade intra-aglomeração transfronteiriça de Foz do Iguaçu/ Ciudad Del Este/Puerto Iguazu. São Paulo e Rio Grande do Sul aparecem atrás, revelando uma forte conexão fronteiriça com alguns países do Cone Sul, majoritariamente o Paraguai (IPARDES, 2008). Foz do Iguaçu se destaca como o município com o mais elevado número de pessoas envolvidas neste movimento pendular:

[...] considerando-se origem e destino: 16.195 pessoas se movimentam no município para trabalho e/ou estudo, sendo que $80 \%$ (12.900 pessoas) correspondem a saídas majoritariamente para o Paraguai, e 20\% (3.295 pessoas) a entradas em grande parte vindas de Santa Terezinha do Itaipu (1.518 pessoas). Cabe observar que, com essa fonte de informações, Foz do Iguaçu tem seus fluxos limitados apenas a pessoas procedentes de municípios brasileiros, o que pode escamotear um papel receptor de população estrangeira (IPARDES, 2008, p. 41).

Com o intuito de verificar esta realidade, buscamos o número de pessoas que utilizam o transporte coletivo de Foz do Iguaçu a Puerto Iguazu e Foz do Iguaçu a Ciudad Del Este. Das quatro empresas que realizam a linha Foz do Iguaçu/Puerto Iguazu, apenas uma não nos forneceu os dados. Entretanto, a Tabela 3 oferece uma amostra dos deslocamentos realizados por ônibus entre ambas as cidades. 
Tabela 3 - Média diária de passageiros entre Foz do Iguaçu/ Puerto Iguazu e Foz do Iguaçu/Ciudad Del Este: janeiro-junho de 2011

\begin{tabular}{c|c|c}
\hline Linhas & Média mensal de passageiros & Média diária de Passageiros \\
\hline Foz-Puerto Iguazu & 18.390 & 613 \\
\hline Puerto Iguazu- Foz & 17.670 & 589 \\
\hline Foz-Ciudad Del Este & 47.550 & 1.585 \\
\hline Ciudad Del Este-Foz & 49.710 & 1.657 \\
\hline Total & 133.320 & 4.444 \\
\hline
\end{tabular}

Fonte: Viação Itaipu, Cruzeiro Del Norte, Tres Fronteras Transportes Urbanos, Nuestra Senhora de La Assunción, Rafain, Riza e Celeste (Pluma) Transportes Urbanos, 2011

Verifica-se uma média de 613 pessoas deslocando-se para a cidade de Puerto Iguazu diariamente, enquanto 589 saem de Puerto Iguazu com destino a Foz do Iguaçu todos os dias. Estes números são constituídos em grande parte por turistas, que se hospedam em Foz do Iguaçu e deslocam-se à cidade argentina com fins de lazer, ou, estando hospedados em Puerto Iguazu, utilizam o transporte coletivo para visitar Foz do Iguaçu.

É importante ressaltar que o fluxo entre estas duas cidades é consideravelmente maior, pois os dados da tabela representam apenas uma das maneiras de deslocamento, já que uma grande frota de vans e ônibus de turismo efetuam este traslado, além dos automóveis particulares que diariamente passam pelas aduanas entre ambos os países. O deslocamento entre as cidades brasileira e argentina não é majoritariamente motivado por trabalho e/ou estudo. Puerto Iguazu, embora seja menor que Foz do Iguaçu, também é uma cidade estruturada para o atendimento turístico, além da atratividade de seu comércio por conta dos preços.

Quando se observam os dados das pessoas que utilizam o transporte coletivo entre as cidades de Foz do Iguaçu e Ciudad Del Este, verifica-se que são maiores que as anteriores, já que a dinâmica entre estas cidades ocorre com base no trabalho e no consumo. A Tabela 3 nos revela que 1.585 pessoas deslocam-se de Foz do Iguaçu para Ciudad Del Este diariamente, enquanto 1.657 pessoas realizam o trajeto contrário todos os dias. Aqui podemos afirmar que o grande número dos passageiros que realizam este deslocamento é para trabalhar ou efetuar compras. A Figura 3 apresenta a média diária do fluxo e origem das pessoas com destino a Foz do Iguaçu. 
Figura 3 - Média diária de deslocamentos em direção a Foz do Iguaçu: janeiro/julho 2011

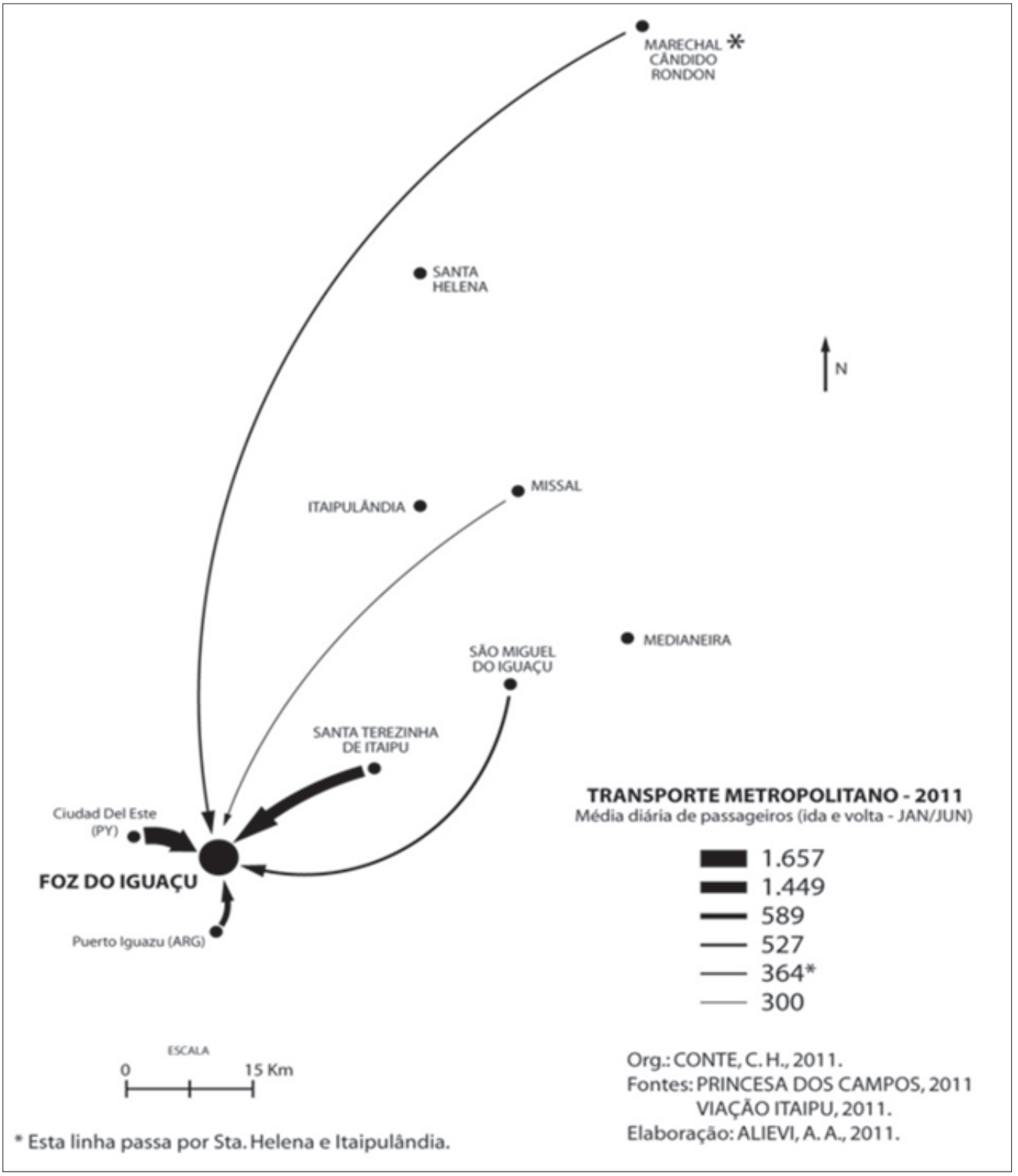

A fim de melhor compreender a motivação das pessoas que utilizam o transporte coletivo com destino a Ciudad Del Este, realizamos uma pesquisa qualitativa durante dois dias, entrevistando 20 pessoas no interior dos ônibus enquanto realizavam o deslocamento de Foz do Iguaçu para Ciudad Del Este. Entre os abordados, 70\% tinham como objetivo o trabalho e apenas uma pessoa não estava diretamente ligada ao setor comercial (Quadro 1). Estes dados confirmam a pesquisa do Ipardes (2008), onde é apontado o trabalho como principal motivação da mobilidade pendular existente entre Foz do Iguaçu e Ciudad Del Este. 
Quadro 1 - Destino dos passageiros da linha Foz do Iguaçu / Ciudad Del Este

\begin{tabular}{|c|c|c|c|}
\hline Objetivo da viagem & $\%$ & Especificação do trabalho & $\begin{array}{c}\text { Motivação para trabalhar no } \\
\text { Paraguai }\end{array}$ \\
\hline Trabalho - 14 pessoas & 70 & Lojas de eletrônicos - 05 pessoas & Trabalhar a anos e estar acostumado \\
\hline Compras - 05 pessoas & 25 & $\begin{array}{l}\text { Shopping Monalisa - } 02 \text { pessoas } \\
\text { (01 como gerente da seção de } \\
\text { bebidas) }\end{array}$ & Satisfação com o emprego \\
\hline $\begin{array}{l}\text { Visitar parentes - } 01 \\
\text { pessoa }\end{array}$ & 5 & $\begin{array}{l}\text { Lojas de autoservice - } 03 \\
\text { pessoas }\end{array}$ & $\begin{array}{l}\text { Falta de oportunidades em Foz do } \\
\text { Iguaçu }\end{array}$ \\
\hline & & $\begin{array}{l}\text { Coordenador de funcionários da } \\
\text { rede de fast food Burger King - } \\
01 \text { pessoa }\end{array}$ & \multirow{3}{*}{$\begin{array}{l}\text { Salário maior que os pagos em Foz } \\
\text { do Iguaçu }\end{array}$} \\
\hline & & Administrador - 02 pessoas & \\
\hline & & Professor particular - 01 pessoa & \\
\hline
\end{tabular}

Fonte: Entrevistas realizadas durante os dias 07,10 e 11 de agosto de 2011.

Em relação ao deslocamento por meio de transporte coletivo com origem em Ciudad Del Este e destino a Foz do Iguaçu (Quadro 2), verificou-se a repetição da motivação: $82 \%$ dos abordados afirmaram estar indo a Foz do Iguaçu para trabalhar ${ }^{2}$. Entre os trabalhadores, dois ocupam-se no comércio, enquanto os demais se dividem entre empregada doméstica, diarista, babá e pedreiro. Além de trabalhadores, dois dos entrevistados estavam atravessando a fronteira para lazer.

Quadro 2 - Destino dos passageiros da linha Ciudad Del Este/ Foz do Iguaçu

\begin{tabular}{|c|c|c|c|c|}
\hline $\begin{array}{l}\text { Pessoas } \\
\text { abordadas }\end{array}$ & $\begin{array}{l}\text { Pessoas que } \\
\text { responderam }\end{array}$ & $\begin{array}{l}\text { Objetivo da } \\
\text { viagem }\end{array}$ & $\begin{array}{l}\text { Especificação do } \\
\text { trabalho }\end{array}$ & $\begin{array}{c}\text { Motivação para trabalhar em } \\
\text { Foz do Iguaçu }\end{array}$ \\
\hline \multirow{5}{*}{14} & \multirow{5}{*}{11} & $\begin{array}{c}\text { Trabalho - } 09 \\
\text { pessoas }\end{array}$ & $\begin{array}{c}\text { Empregada } \\
\text { doméstica - } 03 \\
\text { pessoas }\end{array}$ & O salário é maior \\
\hline & & \multirow{4}{*}{$\begin{array}{c}\text { Passear - } 02 \\
\text { pessoas }\end{array}$} & Diarista - 01 pessoa & Falta de empregos no Paraguai \\
\hline & & & Babá - 01 pessoa & \\
\hline & & & $\begin{array}{l}\text { Pedreiro - } 02 \\
\text { pessoas }\end{array}$ & \\
\hline & & & $\begin{array}{c}\text { Vendedor Vila } \\
\text { Portes - } 02 \text { pessoas }\end{array}$ & \\
\hline
\end{tabular}

Fonte: Entrevistas realizadas durante os dias 07,10 e 11 de agosto de 2011.

2 Neste trajeto foram abordadas 14 pessoas, todavia, apenas 11 se dispuseram a responder as questões. Notou-se que os paraguaios não se sentem seguros em falar a respeito deste assunto, já que um dos abordados questionou a possibilidade de a pesquisa ser encomendada pela Polícia Federal. 
Lima (2011), em sua tese de doutorado, realizou pesquisa para conhecer o perfil dos trabalhadores de Foz do Iguaçu que se deslocam diariamente pela Ponte da Amizade para Ciudad Del Este. Para definir a amostra desta pesquisa, o autor baseou-se no censo demográfico de $2000^{3}$, onde é apontado o número de residentes em Foz do Iguaçu que estudavam ou trabalhavam no Paraguai, ou seja, 10.330 pessoas. A Tabela 4 aponta a ocupação dos brasileiros que trabalham no Paraguai, assim como os rendimentos mensais.

Tabela 4 - Trabalhadores brasileiros que atuam no Paraguai por setor de atividades e salário médio: 2000

\begin{tabular}{l|c|c|c}
\hline \multicolumn{1}{c|}{ Setor } & \multicolumn{2}{|c|}{ Trabalhadores } & Renda Média R\$ \\
\hline Agricultura & Total & $\%$ & 1223,33 \\
\hline Indústria de transformação & 453 & 4,4 & 1066,05 \\
\hline Construção civil & 479 & 4,6 & 1078,29 \\
\hline Comércio & 244 & 2,4 & 1017,28 \\
\hline Alojamento e alimentação & 5839 & 56,5 & 585,18 \\
\hline Transporte & 404 & 3,9 & 324,90 \\
\hline Outros & 2478 & 24,0 & 932,16 \\
\hline Total & 433 & 4,2 & 843,49 \\
\hline
\end{tabular}

Fonte: IBGE apud Lima (2011, p.126).

Nota-se o predomínio de trabalhadores brasileiros atuando no setor de comércio e transporte, com pouca participação da agricultura e atividades relacionadas, assim como da indústria de transformação. Verifica-se, na Tabela 4, que os rendimentos médios em 2000 ultrapassavam a marca dos mil reais, valores expressivos naquele período.

Dos 317 entrevistados por Lima (2011), verificou-se que o trabalhador de Ciudad Del Este que reside no Brasil é majoritariamente do gênero masculino, em uma proporção de $66 \%$ de homens e $34 \%$ de mulheres. Da amostra pesquisada, a maior parte dos trabalhadores que cruzavam a ponte residia em Foz do Iguaçu (95,9\%). Apenas dez entre os entrevistados moravam em Santa Terezinha de Itaipu e dois em Ciudad Del Este.

No que diz respeito ao setor de atividade, o levantamento de Lima (2011), de acordo com a Tabela 5, revelou a predominância do comércio e serviços, com 73,4\% dos entrevistados se ocupando nestas atividades.

3 Lima (2011, p. 127), explicita que: “Os dados do Censo de 2000 serviram como referência para projetar uma amostra que fosse significativa para a análise da população, uma vez que o Censo de 2010 ainda não havia sido coletado quando da realização do trabalho de campo. O IBGE projetava uma população de 325.137 pessoas para Foz do Iguaçu em 2009, de modo que, mantendo-se a mesma proporção de 2000, podia-se esperar uma população de 12.992 pessoas que trabalhariam em Ciudad Del Este enquanto residiam em Foz do Iguaçu. Contudo, já no início do trabalho de campo, notou-se que o universo de trabalhadores brasileiros no Paraguai era muito inferior ao total inferido. Em entrevista com o delegado regional da Secretaria do Trabalho do Estado do Paraná, foi indicado como número provável de trabalhadores, para o ano de 2010, um contingente igual ou inferior a 5 mil pessoas. Na Agência do Trabalhador, também tivemos a mesma resposta, com um número aproximado de cinco mil pessoas. Questionando as referidas autoridades, a resposta relacionava a diminuição no número de trabalhadores brasileiros em Foz do Iguaçu com a maior rigidez da legislação trabalhista no Paraguai, como uma suposta lei de cotas de trabalhadores paraguaios nas lojas de Ciudad Del Este. 
Tabela 5 - Ocupação dos brasileiros que trabalham no Paraguai: 2011

\begin{tabular}{c|c|c}
\hline Setor & Frequência & $(\%)$ \\
\hline Comércio e Serviços & 248 & 73,4 \\
\hline Transporte & 10 & 3,0 \\
\hline Indústria & 07 & 2,1 \\
\hline Alojamento e Alimentação & 11 & 3,3 \\
\hline Construção Civil & 03 & 0,9 \\
\hline Serviços Pessoais e Domésticos & 05 & 1,5 \\
\hline Outro & 02 & 0,6 \\
\hline "Laranja” (25) & 52 & 15,4 \\
\hline Total & 338 & 100 \\
\hline
\end{tabular}

Fonte: Lima (2011, p.132).

Os trabalhadores do comércio em Ciudad Del Este recebem uma renda superior aos que desenvolvem a mesma atividade em Foz do Iguaçu. Porém, se compararmos estes dados com as informações de 2000 (Tabela 4), percebe-se que ocorreu redução nos salários, que pode ser explicada, de acordo com o autor, pela subdeclaração nas respostas dadas aos questionários, mas também pela redução expressiva do movimento na fronteira ao longo da década de 2000.

Diante do exposto, concorda-se que esta aglomeração transfronteiriça:

[...] assenta-se em um espaço heterogêneo, diverso e assimétrico, sendo ponto de passagem e origem de diversos fluxos de pessoas e mercadorias de variadas procedências. A presença dos rios Paraná e Iguaçu delineia a fronteira física entre os países, sem criar obstáculos às intensas relações econômico-sociais, tampouco ao desempenho de papéis específicos dessas cidades que compõem um espaço ocupado em continuidade e com condições diferenciadas de inserção na divisão internacional do trabalho. Como acontece em regiões de fronteira, a mobilidade humana é traço característico tanto no que se refere aos movimentos cotidianos de trabalhadores e consumidores quanto na diversidade étnica, fazendo com que os próprios limites fronteiriços se esvaneçam no feixe das relações cotidianas (IPARDES, 2008, p. 131).

Esta aglomeração define um contexto geopolítico de grande importância, construind o uma posição de centralidade na região por meio de sua localização geográfica, favorecendo Foz do Iguaçu pelas funções realizadas na interseção entre os três países. Rolim (2004, p. 1) ao abordar o caso da aglomeração transfronteiriça de Foz do Iguaçu, aponta uma situação de legalidade, mediante relações de cooperação ou coexistência pacífica entre os países, caracterizando-se por uma dada mobilidade de pessoas, bens, serviços e capitais, controladas pelas barreiras alfandegárias e por outras restrições legais a mobilidade dos recursos, bens e serviços. 


\section{CONSIDERAÇÕES FINAIS}

A localização de Foz do Iguaçu no extremo oeste paranaense e a existência de pequeno número de municípios sob sua influência indicam que esta rede urbana regional mantém uma dinâmica, contudo, de forma limitada aos sete municípios, reforçando, neste sentido, a dinâmica existente na aglomeração fronteiriça. É este aspecto que diferencia a inserção de Foz do Iguaçu na rede de cidades, já que muitas vezes as relações existentes com as cidades fronteiriças são muito mais intensas do que as mantidas com as cidades de sua rede regional.

Se a oferta de bens e serviços para localidades de sua rede urbana é relativamente restrita, por outro lado, outras dinâmicas econômicas e sociais ocorrem entre Foz do Iguaçu e as cidades fronteiriças de Ciudad Del Este, no Paraguai, e Puerto Iguazu, na Argentina, que constituem um aglomerado urbano de fronteira.

A pesquisa realizada sobre os movimentos pendulares nesta aglomeração indicou grande movimentação de brasileiros em direção a Ciudad Del Este, mas o movimento contrário também ocorre. Diferentemente da legislação paraguaia, a brasileira condena a ilegalidade dos patrões que contratam paraguaios sem registro e garantias legais. Entretanto, os próprios paraguaios não questionam a situação. O motivo deste silêncio é o salário, visto que em Foz do Iguaçu eles recebem praticamente o dobro do que receberiam no Paraguai. Lá, o salário médio é de $R$ \$ 350,00, enquanto que em Foz do Iguaçu é de cerca de $\mathrm{R} \$ 600,00$.

Os registros que apresentam a entrada de paraguaios para trabalhar em Foz do Iguaçu não condizem com a realidade, já que, de acordo com o Ministério do Trabalho e Emprego, o número de paraguaios que tiveram autorizações concedidas para trabalhar legalmente no Brasil, entre 2008 e 2011, soma apenas 130. Como mencionado no decorrer do trabalho, os paraguaios não buscam a legalidade e o que se visualiza, tanto no percurso entre os dois países quanto nas ruas de Foz do Iguaçu, é um número cada vez maior de paraguaios buscando ocupações diversas na cidade.

A aglomeração urbana da fronteira, que constitui uma ocupação contínua e fortemente articulada, define um contexto geopolítico de grande importância, construindo uma posição de centralidade através de sua localização geográfica, atingindo um porte, uma dinâmica econômica e de relações internacionais que a aproximam das grandes aglomerações urbanas nacionais.

No que diz respeito ao Brasil, este assume importância pela concentração populacional e geração de riquezas provenientes de um setor terciário diversificado e da produção de energia elétrica. Suas características particulares, articuladas aos múltiplos processos, ordens e fluxos, torna evidente a complexidade da gestão deste espaço, que sobrepuja o âmbito local, regional e até mesmo o estadual, constituindo uma articulação de complexa formatação, considerando os instrumentos existentes. Nesta discussão, concorda-se com Lima (2011), que aponta a necessidade de uma estratégia de desenvolvimento regional que contemple todos esses aspectos. 


\section{REFERÊNCIAS}

CORRÊA, R. L. A rede urbana. São Paulo: Ática, 1989.

. Trajetórias geográficas. Rio de Janeiro: Bertrand Brasil, 1997.

. Estudos sobre a rede urbana. Rio de Janeiro: Bertrand Brasil, 2006.

DER. Malha Rodoviária: distâncias rodoviárias das principais cidades. Disponível em: <http://www.der. pr.gov.br/arquivos/File/malha_distancia.pdf>. Acesso em: 07 set. 2011.

FRESCA, T. M. A rede urbana do norte do Paraná. Londrina: Eduel, 2004.

GHIZZO, M. R; ROCHA, M. M. Contextualização dos estudos de mobilidade da população nas ciências humanas. Espaço Plural, ano IX, n.18. jan./jun. 2008.

HARVEY, D. A justiça social e a cidade. São Paulo: Hucitec, 1980.

IBGE. Migração e deslocamento, resultados da amostra, comentário dos resultados. Censo Demográfico 2000. Rio de Janeiro, 2001.

2010.

Sinopse do Censo 2010. Disponível em: <http:/ / www.censo2010.ibge.gov.br>. Acesso em: 21 dez.

IPARDES. Os Vários Paranás - oeste paranaense: o $3^{\circ}$ espaço relevante. Curitiba, 2008.

LIMA, F. R. F. Desenvolvimento regional na fronteira Foz do Iguaçu/BR, Ciudad Del Este/PY. 2011. Tese (Doutorado). Universidade Federal do Paraná, Curitiba, 2011.

MOURA, R. Movimento pendular da população no Paraná: uma evidência da desconexão moradia/ trabalho. Caderno metrópole. São Paulo, v. 12, n. 23, p. 43-64, jan./jun. 2010.

OJIMA, R. Fronteiras Metropolitanas: um olhar a partir dos movimentos pendulares. Revista Paranaense de desenvolvimento, Curitiba, n. 121, p. 109-126, jul./dez. 2011.

PARANÁ. Secretaria de Estado de Planejamento e Coordenação Geral. Coordenadoria de Estudos e Projetos. Definições de critérios para a determinação de regiões metropolitanas, aglomerações urbanas e microrregiões. Curitiba: SEPL, 1991.

RIBEIRO, M, A, C. A complexidade da rede urbana Amazônica: três dimensões de analise. 1998. Tese (Doutorado). Universidade Federal do Rio de Janeiro, Rio de Janeiro, 1998.

ROLIM, C. Como analisar as regiões transfronteiriças? Esboço de um enquadramento teórico-metodológico a partir do caso de Foz do Iguaçu. TD Nereus, São Paulo, 2004.

SANTOS, M. A natureza do espaço: técnica e tempo, razão e emoção. São Paulo: Hucitec, 1996.

Recebido em 04/04/2012

Aceito para publicação em 09/10/2012 